\title{
TECHNO-ECONOMIC ANALYSIS OF AMMONIA PRODUCTION VIA INTEGRATED BIOMASS GASIFICATION
}

\author{
$\underline{\text { Jim Andersson }}^{1}$ and Joakim Lundgren ${ }^{1}$ \\ ${ }^{1}$ Luleå University of Technology, Division of Energy Science \\ jim.andersson@ltu.se \\ +46920493916
}

\begin{abstract}
Ammonia $\left(\mathrm{NH}_{3}\right)$ can be produced by synthesis of nitrogen and hydrogen in the Haber-Bosch process, where one of the challenges is the availability of a sustainable and economic hydrogen source. Natural gas is currently the main feedstock for $\mathrm{NH}_{3}$ production and a more environmentally sustainable alternative could be the use of biomass-based synthesis gas. The main objective of this paper is to perform a techno-economical evaluation of the production of biomass-based $\mathrm{NH}_{3}$ from the integration of a pressurized entrained flow biomass gasifier (PEBG) in a paper and pulp mill. The synthesis and ammonia production were modelled in Aspen Plus, while a process integration model based on Mixed Integer Linear Programming (MILP) of an existing pulp and paper mill in Sweden was used to analyse the effects on the overall energy system of the mill. The approach to the integration between the two models was an iterative procedure, the most important constraint being the conservation of the steam balance in the mill. The results showed that the overall system efficiency (calculated in terms of electricity equivalents) is increased by $10 \%$-units compared to the original operation of the mill where also the operation of a non-integrated gasification plant for ammonia production is included. The integrated process configuration produces $\mathrm{NH}_{3}$ to a cost of $458 € / \mathrm{t}$ and requires a relative high selling marginal to be economically feasible.
\end{abstract}

Keywords: Biomass, Gasification, Ammonia, Integration Pulp and paper mill

\section{NOMENCLATURE}

Abbreviations

ASU Air separation unit

BAU Business-as-usual

$\begin{array}{ll}\text { BB } & \text { Bark boiler } \\ \text { HP } & \text { High pressure } \\ \text { HRB } & \text { Heat recovery boiler } \\ \text { IRR } & \text { Internal rate of return } \\ \text { MILP } & \text { Mixed integer linear programming } \\ \text { MP } & \text { Medium pressure } \\ \text { LP } & \text { Low pressure } \\ \text { PEBG } & \text { Pressurized entrained flow gasifier } \\ \text { PI } & \text { Process integration } \\ \text { S-A } & \text { Stand-alone } \\ \text { WACC } & \text { Weighted average cost of capital }\end{array}$

\section{INTRODUCTION}

Ammonia $\left(\mathrm{NH}_{3}\right)$ is one of the most produced inorganic chemicals worldwide, with a total global production of 109 Mt in 2009 [1]. Ammonia can be produced via synthesis of nitrogen and hydrogen using the Haber-Bosch process. The current most common source of hydrogen is fossil natural gas reforming. An alternative, renewable source is thermal gasification of biomass. Pressurized entrained flow biomass (PEBG) gasification provides the opportunity to produce a high quality syngas with a technology suitable for large production capacities.

The energy intensive pulp and paper industry provides an excellent opportunity for polygeneration of biomass-based chemicals, due to the existing infrastructure for biomass handling and the possibility to fully exploit by-products. Furthermore, the industry is facing increased energy prices and stronger competition on raw materials [2]. It is therefore important to find new options to add extra streams of revenues to their existing production.

The main aim of this work is to investigate potential technical and economic benefits deriving from the integration of a PEBG plant for ammonia production in an existing Swedish pulp and paper mill. The result is compared with ammonia production in a stand-alone biomass gasifier. The objectives are to find possible and measurable added 
values in the integrated system solutions compared to stand-alone units and the original operation of the mill. This is done by calculating the overall system efficiency and evaluating the process economics by calculating the ammonia production costs complemented with a cash flow analysis.

\section{MATERIAL AND METHOD}

A detailed overall process integration (PI) model of an existing pulp and paper mill in northern Sweden was used to study the potential integration of a pressurized entrained flow biomass gasifier plant for ammonia production. The $\mathrm{PI}$ model is built in a Java-based software - ReMIND, based on mixed integer linear programming (MILP). The model is composed of branches and nodes, where each node describes a steam process unit in the mill. These are represented by a linear equation expressing the materials and energy balances of the specific unit. Branches are used to connect steam generating units and steam consumers, and represent the network of material and energy flow in the mill. The PI model of the existing mill configuration was validated against operational data (the model and model development are further described in [3]). A detailed Aspen Plus process model was used to model energy and material balances of the fuel pre-treatment, biomass gasifier, syngas conditioning and ammonia synthesis. The balances from the Aspen Plus model was supplied as input to the PI model, where the most important modelling constraint was to maintain the process steam balance of the mill. An iterative approach was adopted when combining the two models.

\subsection{Pulp and paper mill}

The mill consists of two major processing lines: the fiber line and the chemicals recovery loop. The fiber processing line extends from the digester to the outgoing pulp and paper, see Figure 1.

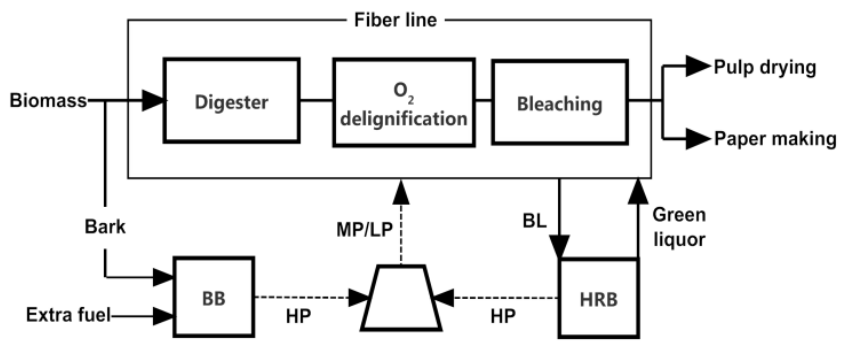

Figure 1 Conventional fiber line and chemical looping.

In the processing line, cooking chemicals (white liquor) and heat are used to dissolve the binding agent in wood (lignin) in order to release the cellulose fibers needed as raw material for the pulp and paper. The black liquor (BL) is a by-product from the pulp making, containing the spent cooking chemicals and organic matter. The recovery of these chemicals is necessary to make the process economically feasible. The solid content of the $\mathrm{BL}$ is concentrated in multi-effect evaporators before being burned in a heat recovery boiler (HRB). The combustion of organics provides energy to produce high pressure (HP) steam and to carry out the reduction reactions to recover cooking chemicals. Sodium hydroxide $(\mathrm{NaOH})$ and sodium sulfide $\left(\mathrm{Na}_{2} \mathrm{~S}\right)$ are the main component in the white liquor solution, generated by passing the recovered cooking chemicals through the causticizing plant. In process of concentrating the $\mathrm{BL}$, rosin soap is precipitated. The rosin soap is further processed into tall oil, used for fuel in the lime kiln.

More HP steam is produced in the bark boiler (BB) using the internal surplus of bark with the required extra biomass (or oil) to cover the steam demand of the mill. The produced HP steam expands to medium pressure (MP) and low pressure (LP) steam in a back-pressure turbine. A small quantity of the steam is extracted at 30 bar for soot-blowing for the HRB, while MP and LP steam are consumed in the internal processes in the pulp and paper mill. The backpressure turbine has a power output of $35 \mathrm{MWe}$.

\subsection{Pre-treatment and gasification modelling}

The syngas for the ammonia production plant is generated via a $243 \mathrm{MW}_{\text {th }}$ pressurized entrained flow biomass gasifier (PEBG). This gasification technology yields a nearly tar and methane free syngas, due to the high temperature inside the reactor.

Before the fuel is supplied to the reactor, the moisture content and the particle size must be reduced. In Aspen Plus a black-box modelling approach is applied for the drying and for the size reduction (milling). The incoming biomass is specified according to the ultimate and proximate analysis of the fuel. The dryer is modelled as an indirectly heated rotary dryer, with a specific power consumption of $15 \mathrm{kWh}$ per wet tonne of biomass [4]. The moisture content in biomass is reduced from above $40 \%$ to $8 \%$.

Particle sizes smaller than $1 \mathrm{~mm}$ are required for entrained flow biomass gasifiers. According to [5], up to 1$3 \%$ of the thermal input of biomass (based on LHV) can be required in terms of specific electricity consumption for reducing the particle size of woody biomass to less than 1 $\mathrm{mm}$. The power consumption increases significantly if the required particles sizes are even smaller. In the modelling the power required for this operation was assumed to be $3 \%$ of biomass thermal input.

Biomass powder was assumed to be pressurized using screw feeders, which require an inert gas as well as electricity. According to [6], the specific electricity consumption is $0.02 \mathrm{~kW}_{\mathrm{el}}$ per $\mathrm{kW}_{\text {th }}$ of biomass for pressurization of biomass powder up to 40 bar. 
Usually nitrogen is an undesired inert gas in various gasification synthesis applications, but not for ammonia synthesis as it is produced by the reaction between $\mathrm{N}_{2}$ and $\mathrm{H}_{2}$ [7]. The use of air as gasification agent would drastically decrease syngas quality, the alternative being pure oxygen (imported or from an installed air separation unit). The uses of oxygen as gasification agent and small biomass particles in a pressurized environment are the main features of high temperature gasification process leading to a high quality syngas. Furthermore, a molar ratio between hydrogen and nitrogen of 3 to 1 is optimal for ammonia production [8], but this ratio could not be controlled if air were used. Oxygen was therefore chosen as gasification agent, produced by a cryogenic air separation unit (ASU) in which the power demand for producing oxygen with $99.6 \mathrm{~mol} \%$ purity is $1.0 \mathrm{MW}_{\mathrm{e}}$ per $\mathrm{kg}-\mathrm{O}_{2} / \mathrm{s}$ [9]. Downstream the gasifier and the gas cleaning units, nitrogen from the ASU is mixed with the nearly pure stream of hydrogen to the desired molar ratio.

The PEGB unit was modelled in a detailed manner by treating the dominant reaction steps in the gasifier separately, i.e. drying, pyrolysis, combustion and gasification. The pyrolysis step is modelled using empirical relationships by an approach developed and described in [10]. Furthermore, equilibrium restrictions are implemented to prevent underestimations of the methane and tar content in the outgoing syngas. This approach provides a better simulation of a pressurized entrained flow reactor [11]. A gasification pressure level of 30 bar(a) was assumed in the model. The temperature of the raw syngas leaving the reactor before entering the quench was assumed to be $1200^{\circ} \mathrm{C}$. The quench section partially quenches the syngas down to $500^{\circ} \mathrm{C}$ using water jets and a water reservoir where the syngas is bubbled through. After the quench the residual heat is recovered for steam generation. A schematic process overview of the gasification plant is shown in Figure 2.

\subsection{Gas conditioning and ammonia synthesis}

A water gas shift (WGS) reactor is used to increase the hydrogen content in the syngas. The shift process consists of one high temperature and one low temperature catalytic reactor, where hydrogen and carbon dioxide are produced by the reaction between carbon monoxide and water in the syngas and from the supplied 30 bar steam.

An acid gas removal (AGR) unit is placed after the shift reactor in order to remove any acid gas contaminations as well as $\mathrm{CO}_{2}$. The AGR unit uses cooled methanol as a physical solvent to remove the unwanted impurities and gas species similar to the Rectisol ${ }^{\circledR}$ process [9].

As a final purification step, a liquid nitrogen wash (or $\mathrm{N}_{2}$ wash) is used. The $\mathrm{N}_{2}$ wash is located downstream the AGR unit and uses the already cooled gas stream (below $-50^{\circ} \mathrm{C}$ ).
Methanol and the remaining traces of $\mathrm{CO}_{2}$ in the syngas need to be removed before the $\mathrm{N}_{2}$ wash to avoid freezing problems in the cold box heat exchanger [8]. The main task for the $\mathrm{N}_{2}$ wash is to remove the remaining CO content, because it acts as a poison for the ammonia catalyst [8]. Pressurized nitrogen and the syngas are cooled down against the product streams (outgoing syngas and offgases). As a result, the nitrogen will be liquefied and then will be fed to the top of the wash column. The cooled syngas enters at the bottom of the column, where inert gases such as methane and argon will condensate from the syngas whilst the liquefied nitrogen removes the carbon monoxide. An additional nitrogen stream is mixed with the outgoing syngas to achieve the desired 3:1 ratio between $\mathrm{H}_{2}$ and $\mathrm{N}_{2}[8]$.

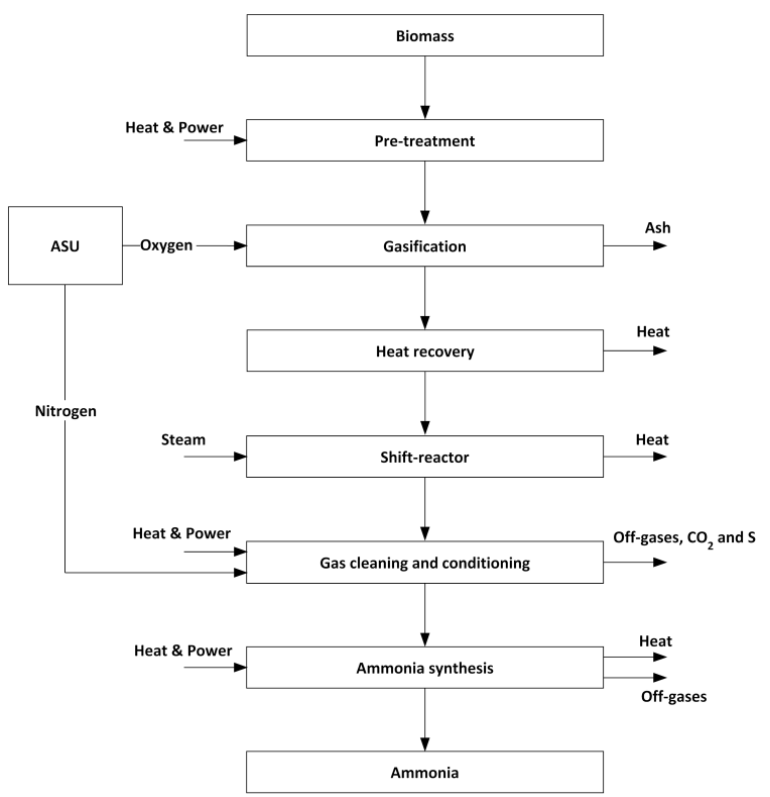

Figure 2 Schematic model over the gasification based ammonia production plant.

The syngas is pressurized to the operating pressure of the ammonia catalyst (180 bar) before entering the synthesis loop. The ammonia synthesis takes place over an iron promoted catalyst [7], modelled using a Gibbs reactors with an outgoing gas temperature of $440^{\circ} \mathrm{C}$. Typically the conversion efficiency is of the order of $20-30 \%$ per pass, and recycling of the unreacted gases is necessary to increase the ammonia production [12]. The ammonia reaction is exothermic, thus cooling of the outgoing gases generates high quality steam [7]. The produced ammonia is separated from the unreacted gases by condensation in a refrigeration system. Part of the recycled gas needs to be purged to avoid inter gas accumulation in the synthesis loop [7]. To compensate for the pressure drop over the catalyst, the recycled gas is recompressed to 180 bar before it is mixed with the incoming syngas. 


\subsection{Case descriptions}

A pulp mill system configuration where the bark boiler is removed and replaced by a PEBG unit for ammonia production was evaluated (Case A). The available heat surplus from the gasification processes is only suitable to be recovered as MP and LP steam. The high pressure steam $\left(440^{\circ} \mathrm{C}\right.$ and $\left.57 \mathrm{bar}\right)$ generated by the boilers in the mill is used to produce electricity and to some extent soot-blowing of the HRB, whilst MP and LP steam are necessary for the process units in the pulp and paper making. The integration was therefore done with the constraint that the MP and LP steam balance of the mill is unaltered. The bark originally used in the bark boiler is used as fuel in the gasification plant together with an additional amount of biomass.

Furthermore, it was assumed that off-gas from the synthesis loop together with tail gas from the $\mathrm{N}_{2}$-wash can substitute the tall oil used in the lime kiln. The surplus tall oil can be sold on the market as an alternative to heavy fuel oil.

Case $A$ is compared against a stand-alone gasification plant (S-A) and the original operation of the pulp and paper mill (BAU). The stand-alone gasification plant has the same thermal gasification capacity and ammonia production as Case $A$, but the recovered surplus heat is here assumed to be sold to a local district heating network.

\subsection{Overall energy system}

The overall energy system efficiency is estimated using electricity equivalents, all energy carriers being converted to their electricity equivalents (see Table 1) according to the efficiency of the best-available technologies known to the authors.

Table 1 Power generation efficiencies used for calculation of electricity equivalents.

\begin{tabular}{|l|c|}
\hline Energy carrier & $\begin{array}{c}\text { Power generation } \\
\text { efficiency }\end{array}$ \\
\hline Biomass [13] & $46.2 \%$ \\
\hline Methanol [13] & $55.9 \%$ \\
\hline Ammonia ${ }^{\text {a) }}$ & $49 \%$ \\
\hline Tall oil $^{\text {b) }}$ & $55.9 \%$ \\
\hline Hot water $-95^{\circ} \mathrm{C}[13]$ & $10 \%$ \\
\hline
\end{tabular}

a) Ammonia is converted into its electrical equivalent by multiplying the methanol power generation efficiency with the ratio of the lower heating values between ammonia and methanol.

b) Assumed the same as methanol

The integrated gasification unit (Case $A$ ) is compared to the original operation of the pulp and paper mill (BAU) and the stand-alone ammonia plant (S-A) to analyse the effects on the overall energy system and determine the best alternative for producing $\mathrm{NH}_{3}$ from biomass gasification (i.e. non-integrated or integrated). The material and energy flows for the stand-alone gasification plant (S-A) are therefore included in the overall system efficiency calculation for the BAU. Biomass for pulp making and the final pulp products are not accounted for in the resulting overall energy system efficiency calculations. The system boundaries used for the overall system efficiency calculations is illustrated by the dashed boxes in Figure 3 .

\subsection{Economic calculations and sensitivity analysis}

For the economic calculations it was assumed that the pulp and paper mill is required to invest in a new bark boiler. The incremental capital cost is calculated for Case A, as comparison between a new investment in a bark boiler and an investment in an integrated gasification plant for ammonia production. The energy balances for Cases A include the operational changes in the paper and pulp mill caused by the integration of the gasification plant. Cost and revenues associated with the original operation of bark boiler is included for the BAU, where the cost of operation and maintenance is taken from the "Mill stand-alone case" presented in [14].

Since currently fossil natural gas is the main feedstock used for ammonia production [8], the price of natural gas is a deciding factor for the market price of ammonia. Other factors would control the market if ammonia production is based on renewable resources, such as biomass. Therefore, an estimation of the required ammonia selling price that would make biomass based ammonia production an attractive investment opportunity is instead made. The ammonia selling price is calculated via cash flow analysis at three levels of internal rate of returns (IRR). In the cash flow analysis, a start-up period is considered, where the ammonia production is at $25 \%$ of maximum capacity during year one and increases by $25 \%$-points per year until maximum production capacity is reached. The investment cost is assumed to be paid during a three year construction period. Costs and revenues from other products (electricity, tall oil, district heating, etc) are included in the production cost of ammonia. The required ammonia selling price to receive an internal rate of return (IRR) of $10 \%, 15 \%$ or $20 \%$ is investigated.

The investment cost for equipment and assembly is calculated as the over-night installation cost by the sum of the major units (pre-treatment, gasifier, AGR, etc). The investment costs for each unit have been calculated according to the actual capacity, reference size and reference investment cost according to (1):

$\mathrm{I}=\mathrm{I}_{\text {old }} \cdot\left(\frac{\mathrm{P}}{\mathrm{P}_{\mathrm{old}}}\right)^{\mathrm{n}} \cdot \mathrm{F}$ 
where $I$ and $P$ denotes the investment cost and size, , respectively. The subscripts old represent the reference size or cost. $\mathrm{n}$ is the scale factor and $\mathrm{F}$ is the overall installation factor, accounting for auxiliary equipment and/or extra costs associated with an investment in that specific unit. The investment cost references for the bark boiler and for the major units in the gasification plant is presented in Table 2. The reference investment cost is adjusted to $2012 \mathrm{~s}$ price level, by using the ratio between the Chemical Engineering's Plant Cost Index (CEPCI) of the year 2012 and the $\mathrm{CEPCl}$ of the year in which the reference investments were made.

Table 2 Investment estimates for the major units.

\begin{tabular}{|l|c|c|c|c|}
\hline \multicolumn{1}{|c|}{$\begin{array}{c}\text { Cost Reference } \\
\text { [ref] }\end{array}$} & Size unit & $\begin{array}{c}\text { Ref. } \\
\text { Size }\end{array}$ & $\begin{array}{c}\text { M€ } \\
2012^{\text {(a) }}\end{array}$ & $\begin{array}{c}\text { Scale } \\
\text { factor }\end{array}$ \\
\hline Bark boiler [14] & MWth & 46 & 25 & 0.7 \\
\hline Pre-treatment [15] & Wet t/h & 33.5 & 19 & 0.8 \\
\hline $\begin{array}{l}\text { Air separation unit } \\
\text { [15] }\end{array}$ & $\mathrm{t} \mathrm{O}_{2} /$ day & 1000 & 48 & 0.9 \\
\hline PEBG unit [16] & MWth in & 0.22 & 0.5 & 0.8 \\
\hline $\begin{array}{l}\text { Gas cleaning [17] } \\
\text { feed kg/s }\end{array}$ & 37 & 43 & 0.7 \\
\hline $\begin{array}{l}\text { Synthesis plant } \\
\text { [18] }\end{array}$ & $\begin{array}{c}\text { TPD NH } \\
3\end{array}$ & 1800 & 323 & 0.7 \\
\hline Off-gas boiler [9] & MWth & 355 & 67 & 1.0 \\
\hline $\begin{array}{l}\text { District heating } \\
\text { HEX [9] }\end{array}$ & MW & 355 & 67 & 1.0 \\
\hline
\end{tabular}

a) The reference cost is presented after the conversion to $2012 \mathrm{~s}$ price level, also is the overall installation factor (F) is included in the reference capital investment.

A factor of $42 \%$ is added to the equipment and assembly cost to cover indirect costs for project administration and development, legal permits, engineering, interest during construction, insurance, working capital etc. The annual capital cost is estimated by multiplying the annuity factor with the total investment cost (equipment and assembly plus indirect costs). The weighted average cost of capital (WACC) is used as interest rate for the calculation of the annuity factor. WACC is calculated with the specified financial parameters in Table $\mathbf{3}$ for the bank interest, dept share of investment, return on equity and equity share of investment. The annuity factor method is only used to calculate the ammonia production cost.

A possibly future scenario in which most ammonia production is based on renewable resources (i.e. biomass) would certainly make the price for biomass a determining factor for the market price. The required ammonia selling price to receive a $15 \% \mathrm{IRR}$, is calculated using a biomass cost in the range of $11-44 € / M W h$ (i.e. $50 \%$ decrease up to a $100 \%$ increase of the base value). The method for calculating the capital investment cost has an uncertainty in the range of $\pm 30 \%$ [19]. The required ammonia selling price to receive $15 \%$ IRR, is also investigated for $\pm 30 \%$ change of the gasification plant investment cost.

Table 3 Financial parameters for the value year 2012.

\begin{tabular}{|l|c|}
\hline Financial parameter & Value \\
\hline Bank interest & $8 \%$ \\
\hline Equity share of investment. & $30 \%$ \\
\hline Dept share of investment & $70 \%$ \\
\hline Return on equity & $15 \%$ \\
\hline Annuity factor & $11.8 \%$ \\
\hline Project economic lifetime & 20 years \\
\hline Annual operating hours & $8000 \mathrm{~h}$ \\
\hline Annual operating hours, district heating & $5000 \mathrm{~h}$ \\
\hline
\end{tabular}

\section{RESULTS AND DISCUSSION}

As previously mentioned, two different system configurations using PEBG technology to produce ammonia were studied, one stand-alone plant (S-A) and one integrated into a pulp and paper mill (Case $A$ ). The resulting energy flows for the cases are presented in Figure 3. The overall energy system efficiency (calculated as electricityequivalents) was estimated using the system boundaries represented by dashed boxes in Figure 3. The stand-alone plant (S-A) has the same ammonia production capacity and annual demand for biomass and electricity as the gasification plant in Case $A$. The original operation of the mill (BAU) including the operation of the non-integrated stand-alone plant (S-A) has an overall energy system efficiency of $44 \%$, when the delivery of $188 \mathrm{GWh}$ heat to the district heating system is included. By replacing the bark boiler with the PEBG unit in Case $A$, two additional product streams $\left(\mathrm{NH}_{3}\right.$ and tall oil) are added to mill existing production. This increases the biomass import to the mill by $50 \%$, while the electricity production decreases (due less production of HP steam) while the electricity consumption is almost doubled. Nevertheless, the production of ammonia and the possibility to export surplus tall oil improves the overall system efficiency by $10 \%$-units compared to the co-operation of the BAU and the nonintegrated stand-alone gasification plant (S-A), according to the system boundaries in Figure 3. 


\section{Reference mill (BAU) and Stand-alone PEBG (S-A)}

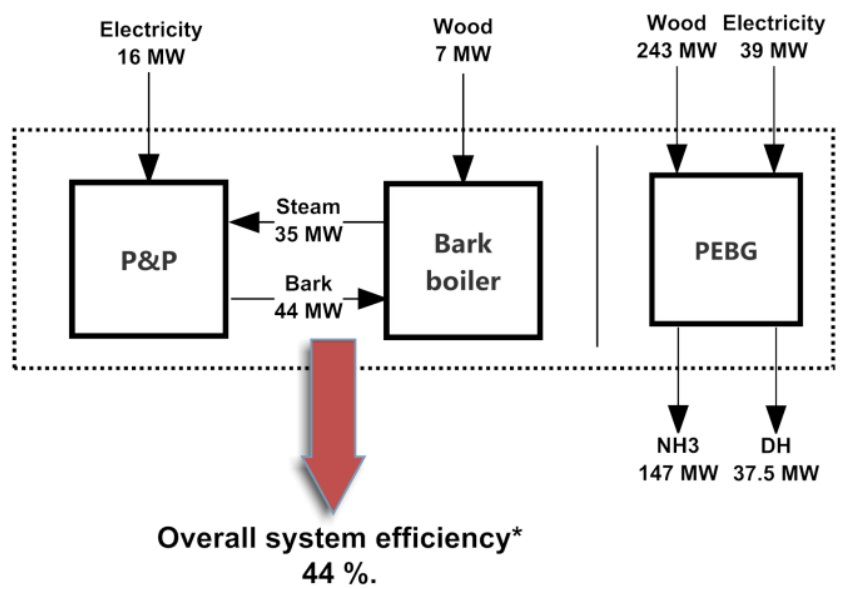

Integrated PEBG (Case A)

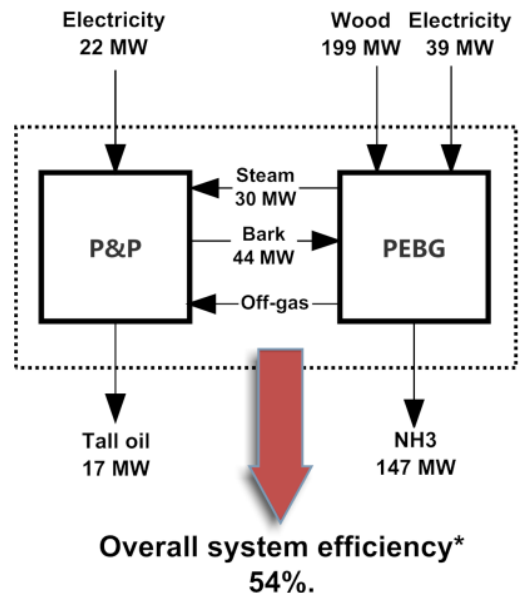

* The overall system efficiency is calculated on an electricity equivalence basis.

Figure 3 Energy and material balance.

Table 4 Estimates for capital investment costs (M€) and production costs (M€ per year).

\begin{tabular}{|c|c|c|c|}
\hline & BAU & S-A & Case A \\
\hline Equipment and assembly & 25 & 300 & 289 \\
\hline Indirect costs & 11 & 125 & 121 \\
\hline Total investment cost & 36 & 425 & 410 \\
\hline Total incremental cost & & 425 & 374 \\
\hline \multicolumn{4}{|c|}{ Production costs in M€ per year ${ }^{(a)}$} \\
\hline Biomass $^{(b)}$ & 1.3 & 43.5 & 35.6 \\
\hline Power $^{(\mathrm{b})}$ & 7.8 & 19.7 & 30.2 \\
\hline$O \& M^{(c)}$ & 1.6 & 17.8 & 17.4 \\
\hline Tall oil $^{(d)}$ & & & -10.0 \\
\hline District heating $^{(\mathrm{d})}$ & & -13.1 & \\
\hline Other costs $^{(\mathrm{e})}$ & 3.2 & 0.8 & 0.8 \\
\hline Subtotal costs (excl. capital) & 13.9 & 68.7 & 73.9 \\
\hline Annual capital costs & 4.2 & 50.3 & 48.5 \\
\hline Total production cost & 18.1 & 119.0 & 122.4 \\
\hline Incremental production cost & & 119.0 & 104.3 \\
\hline Production cost $\left[€ / \mathrm{t} \mathrm{NH}_{3}\right]$ & & 523 & 458 \\
\hline
\end{tabular}

a) A negative sign represents revenue.

b) Biomass cost (22€/MWh) is taken from [20] and the cost for power (63€/MWh) is received from [21].

c) Includes: Operations for chemicals, water treatment, insurance, licenses assumed to be $1 \%$ of the equipment and assembly. Maintenance, $3 \%$ of the equipment and assembly and worker salaries, $6 \mathrm{M€}$ cost for S-A and Case A.

d) Tall oil is assumed to be sold as a substitute for heavy fuel oil. The selling cost for tall oil (74 €/MWh) and district heating (70 €/MWh) are taken from [22]. The DH production $188 \mathrm{GWh}$ annually for the $\mathrm{S}$ A case.

e) Ash handling costs $(57 € / t)$, this also includes cost for heavy fuel oil for BAU.
The calculated capital investment costs and production costs are presented in Table 4 . The gasification unit accounts for $18 \%$ of the total cost for equipment and assembly. In both cases, a train of four gasifier units are assumed to be necessary to ensure the high operational load (8000 hours annually), each unit having one third of the maximum capacity required. The major part $(45 \%)$ of the investment for equipment and assembly resides from the ammonia synthesis production plant. The rest of the investment cost for the major units is almost equally spread between the pre-treatment section, syngas cleaning and conditioning and ASU.

The economic benefit of integrating a PEBG into a pulp mill for ammonia production compared to a stand-alone production unit seems to be small as the total production cost (Table 4) being almost the same for the S-A case and Case $A$. This is because the reduced cost from the possibility to exploit the surplus of bark and the revenue from the tall oil is almost diminished compared to the costs for high electricity consumption in Case $A$ and the revenue from district heating sales in case $\mathrm{S}-\mathrm{A}$. The difference in production cost between the cases $\left(65 € / t \mathrm{NH}_{3}\right)$ is the result of the avoided costs for the deployment and operation of a new bark boiler.

An ammonia selling price in the range of $581-882 € / t$ is required for the stand-alone plant to receive an IRR between $10-20 \%$. Case A consistently requires a lower selling price (509-774 $€ / t$ of ammonia) for the same IRR compared to the S-A case, but the difference between the cases are decreasing when a lower return on the invested capital is assumed. The production cost (excluding the cost for capital) for both cases only accounts for $52-34 \%$ of the 
ammonia selling price. A selling marginal in the range of 48$66 \%$ is therefore required to obtain $10-20 \%-I R R$.

The economic benefits from the integration depend on the economic conditions, as shown in Figure 4. When either the biomass price or the investment cost is changed, the difference between cases varies in the range of $67-130 € / t$ $\mathrm{NH} 3$ produced. A $30 \%$ higher investment cost increases the required selling price for a $15 \%-I R R$ to the same extent as a 95\% increase of the biomass price for Case $A$ and a $75 \%$ increase for case S-A would. In fact, a 75-95\% increase of the biomass price causes a yearly increase of the production cost of 26-32 M€ depending on the case. Whilst, the highest investment cost (+30\%) increases the total capital investment cost by roughly $125 \mathrm{M€}$, this would correspond to an annual capital cost increase of $15 \mathrm{M} €$ (i.e. when the production cost is calculated including the cost for capital using the annuity factor). This indicates that the potential revenues are small compared to the total investment cost.

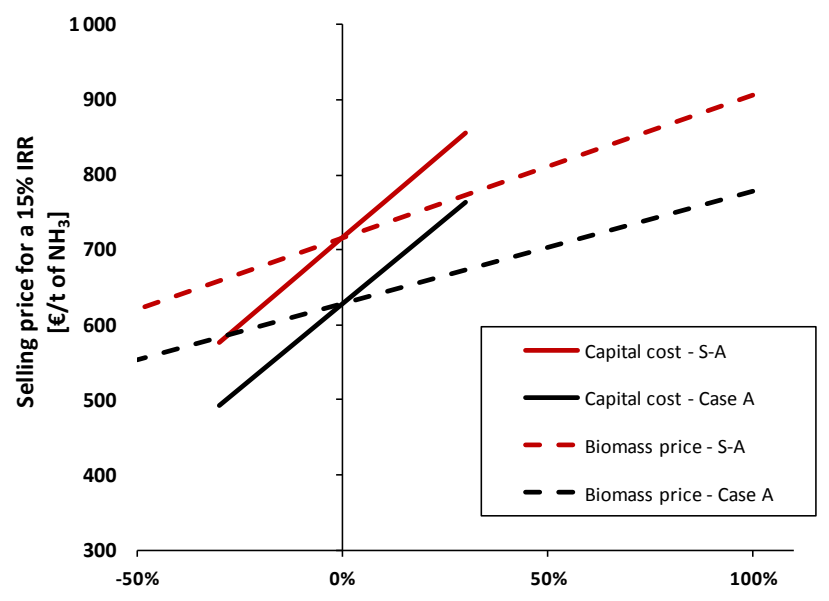

Figure 4 Required selling price for ammonia for an IRR of $15 \%$ when the investment cost and biomass price is varied.

\section{CONCLUSIONS}

Integration of ammonia production via pressurized entrained flow biomass gasification in a Swedish pulp and paper mill was studied (Case A). Replacing the bark boiler with the biomass gasification plant, increases the overall energy system efficiency by $10 \%$-points (calculated on an electricity equivalence basis) compared to the original operation of the mill including the operation of the nonintegrated stand-alone plant (S-A). The economic assessment showed that a relative high ammonia selling price is required for ammonia production to be economically feasible. Case $A$ requires a selling price in the range of $509-774 € / t$ to receive an IRR between $10-20 \%$ and for the S-A plant, an even higher selling price is required. For such IRR-levels, the selling marginal accounts for 48-
$66 \%$ of the ammonia selling price. Approximately $45 \%$ of the total investment cost is directly connected to the investment of the ammonia synthesis loop, indicating that the capacities of the studied system configurations (228 000 t/y $\mathrm{NH}_{3}$ ) are rather small for ammonia production. Larger production plant capacities would most probably be needed to reach economic feasibility at lower ammonia selling price, and lower selling marginal.

\section{ACKNOWLEDGEMENT}

The authors greatly acknowledge the financial contribution from the Nordic Top Research Initiative via the NORD-SYNGAS project. The authors would also like to thank Bio4Energy, a strategic research environment appointed by the Swedish government, for supporting this work.

\section{REFERENCE}

[1] Gilbert P, Thornley P, Alexander S, Brammer J. Biomass gasification for ammonia production. International conference on polygeneration strategies; Sep 2009; Vienna. 2009.

[2] Klugman S, Karlsson M, Moshfegh B. A Scandinavian chemical wood pulp mill. Part 1. Energy audit aiming at efficiency measures. Applied Energy. 2007;84:326-39.

[3] Ji X, Lundgren J, Wang C, Dahl J, Grip C-E. Simulation and energy optimization of a pulp and paper mill - Evaporation plant and digester. Applied Energy. 2012;97:30-7.

[4] Sues A. Are European bioenergy targets achievable? An evaluation based on thermoeconomic and environmental indicators [Doctoral Thesis]. Eindhoven: Eindhoven University of Technology; 2011.

[5] Bergman PCA, Boersma AR, Kiel JHA, Prins MJ, Ptasinski $\mathrm{KJ}$, Janssen FJJG. Torrefaction for entrained-flow gasification of biomass, Report ECN. Petten, Netherlands. ECN-C-05067. 2005.

[6] van der Drift A, Boerrigter H, Coda B, Cieplik MK, Hemmes K. Entrained flow gasification of biomass - Ash behaviour, feeding issues, and system analyses. ECN; April 2004.

[7] Spath PL, Dayton DC. Preliminary Screening - Technical and economic assessment of synthesis gas to fuels and chemicals with emphasis on the potential for biomassderived syngas. Golden, Colorado, USA: National Renewable Energy Laboratory (NREL); 2003.

[8] Higman C, van der Burgt M. Gasification. 2th ed. Burlington, USA: Elsevier Science; 2008. p. 354-5.

[9] Clausen LR, Elmegaard B, Houbak N. Technoeconomic analysis of a low $\mathrm{CO} 2$ emission dimethyl ether (DME) plant based on gasification of torrefied biomass. Energy. 2010;35:4831-42.

[10] Neves D, Thunman H, Matos A, Tarelho L, Gómez-Barea A. Characterization and prediction of biomass pyrolysis 
products. Progress in Energy and Combustion Science. 2011;37:611-30.

[11] Andersson J, Lundgren J. Modeling of a Pressurized Entrained Flow Biomass Gasifier in Aspen Plus. GPE - $3^{\text {rd }}$ International Congress on Green Process Engineering KualaLumpur, Malaysia. 2011.

[12] Ahlgren S, Baky A, Bernesson S, Nordberg $\AA$, Norén O, Hansson P-A. Ammonium nitrate fertiliser production based on biomass - Environmental effects from a life cycle perspective. Bioresource Technology. 2008;99:8034-41.

[13] Tunå P, Hulteberg C, Hansson J, Åsblad A, Andersson E. Synergies from combined pulp\&paper and fuel production. Biomass and Bioenergy. 2012;40:174-80.

[14] Wetterlund E, Pettersson K, Harvey S. Systems analysis of integrating biomass gasification with pulp and paper production - Effects on economic performance, $\mathrm{CO} 2$ emissions and energy use. Energy. 2011;36:932-41.

[15] Hamelinck CN, Faaij APC. Future prospects for production of methanol and hydrogen from biomass. Journal of Power Sources. 2002;111:1-22.

[16] Westerberg P. Personal Communication with Per Westerberg on gasifier investment cost, IVAB. Piteå, Sweden; 2011-01-14:

[17] Ekbom T, Lindblom M, Berglin N, Ahlvik P. Black liquor gasification with motor fuel production - BLGMF. Report, Stockholm, Sweden, Contract No. 4.1030/Z/01-087/2001. 2003.

[18] Bartels J, Pate M. A feasibility study of implementing an ammonia economy. Final report. Grant number: 07S-01. lowa State University; 2008.

[19] Hamelinck CN, Faaij APC, den Uil $H$, Boerrigter $H$. Production of FT transportation fuels from biomass; technical options, process analysis and optimisation, and development potential. Energy. 2004;29:1743-71.

[20] Swedish Energy Agency. Trädbränsle- och torvpriser, Sveriges officiella statistiska meddelanden EN 0307 SM 1201, (in Swedish). Accessed 2012-03-10:

http://energimyndigheten.se/sv/Statistik/Energipriser/

[21] Nord Pool Spot. Average power spot price in Sweden 2010. Accessed 2012-03-10:

http://www.nordpoolspot.com/Market-data1/Elspot/AreaPrices/ALL1/Hourly/

[22] Abrahamsson K, Persson T, Nilsson L, Friberg D. Uppvärmning i Sverige 2012, El R2012:09, (in Swedish). Eskilstuna; Accessed 2012-10-10:

http://www.energimarknadsinspektionen.se/sv/Publikation er/Rapporter-och-PM/rapporter-2012/uppvarmning-i-

sverige-eir-2012-09/ 